University of Nebraska - Lincoln

DigitalCommons@University of Nebraska - Lincoln

Faculty Publications, Department of Psychology

Psychology, Department of

January 1996

\title{
Timing of First Sexual Intercourse: The Role of Social Control, Social Learning, and Problem Behavior
}

\author{
Lisa J. Crockett \\ University of Nebraska-Lincoln, ecrockett1@unl.edu \\ C. Raymond Bingham \\ Michigan State University \\ Joanne S. Chopak \\ Georgia Southern University \\ Judith R. Vicary \\ The Pennsylvania State University
}

Follow this and additional works at: https://digitalcommons.unl.edu/psychfacpub

Part of the Psychiatry and Psychology Commons

Crockett, Lisa J.; Bingham, C. Raymond; Chopak, Joanne S.; and Vicary, Judith R., "Timing of First Sexual Intercourse: The Role of Social Control, Social Learning, and Problem Behavior" (1996). Faculty Publications, Department of Psychology. 233.

https://digitalcommons.unl.edu/psychfacpub/233

This Article is brought to you for free and open access by the Psychology, Department of at DigitalCommons@University of Nebraska - Lincoln. It has been accepted for inclusion in Faculty Publications, Department of Psychology by an authorized administrator of DigitalCommons@University of Nebraska - Lincoln. 
Published in Journal of Youth and Adolescence 25:1 (1996), pp. 89-111. Copyright (C) 1996 Plenum Publishing Corporation/Springer Verlag. Used by permission.

http://www.springerlink.com/content/104945/

Submitted December 1, 1992; accepted August 29, 1994.

\title{
Timing of First Sexual Intercourse: The Role of Social Control, Social Learning, and Problem Behavior
}

\author{
Lisa J. Crockett, ${ }^{1}$ C. Raymond Bingham, ${ }^{2}$ \\ Joanne S. Chopak, ${ }^{3}$ and Judith R. Vicary ${ }^{4}$
}

Prior research has pointed to several distinct processes that may affect the timing of first intercourse among adolescents. In the present study, the role of six hypothesized processes was assessed in a sample of 289 rural adolescent boys and girls. Results support the importance of family socialization and problem behavior for both sexes, the role of biological factors for boys, and the role of social control processes for girls. Two other hypothesized influences-social class and poor psychosocial adjustment-were not supported in either gender. These results indicate that multiple processes influence the timing of first intercourse; thus, they underscore the need for eclectic predictive models that incorporate the multiplicity of influences.

${ }^{1}$ Associate Professor, Department of Human Development and Family Studies, The Pennsylvania State University, University Park, Pennsylvania 16802. Received Ph.D. in Human Development from the University of Chicago. Current research interests include adolescent psychosocial development and risk behaviors. Corresponding author.

${ }^{2}$ Research Assistant Professor, Department of Psychology, Michigan State University, East Lansing, Michigan. Received Ph.D. in Human Development and Family Studies from the Pennsylvania State University. Current research interests include adolescent sexuality and health-related behaviors.

${ }^{3}$ Assistant Professor, Department of Health Science Education, Georgia Southern University, Statesboro, Georgia. Received Ph.D. in Health Education from The Pennsylvania State University. Current research interests include adolescent health.

${ }^{4}$ Associate Professor, Department of Health Education, The Pennsylvania State University, University Park, Pennsylvania. Received Ph.D. in Education from The Pennsylvania State University. Current interests include adolescent substance abuse and pregnancy, as well as community health interventions. 


\section{INTRODUCTION}

Adolescent sexuality continues to be an important social concern because of its connection to adolescent pregnancy and sexually transmitted diseases. The teenage pregnancy rate in the United States is the highest among Western industrialized nations (Jones et at., 1986) and results in approximately half a million births each year (Hayes, 1987). The cost of these births is reflected in reduced educational and occupational attainment, income, and marital stability for the mothers, as well as in increased health risks, academic failure, and behavior problems in their children. Furthermore, sexually active adolescents are known to be at risk for contracting a number of sexually transmitted diseases including HIV infection (Bingham, 1989; D’Augelli and Bingham, 1993).

The timing of an adolescent's first sexual intercourse is a key variable affecting these negative outcomes. Adolescents who initiate sex at younger ages, for example, may be at increased risk for an unintended pregnancy because they are less likely to practice effective contraception (Hayes, 1987; Zelnik and Shah, 1983). Sexually active young adolescents may also be at increased risk for contracting sexually transmitted diseases: a recent survey of adolescent males indicated that boys who initiate sex in early adolescence are less likely to use condoms than those who become sexually active at later ages (Sonnenstein, Pleck, and Ku, 1989). Given the need to prevent early adolescent pregnancy and sexually transmitted diseases, uncovering the factors associated with early initiation of intercourse merits continued study.

Adolescents who postpone first intercourse until their late teens or early twenties may also merit special attention. These adolescents remain virgins after the majority of their peers have initiated intercourse. Hence, studies of these youth may help elucidate strategies for delaying first intercourse. Unfortunately, in most studies of adolescent sexual activity, the "virgin" group includes both postponers who will delay intercourse substantially and others who will have become sexually active by the end of high school. These two groups may be quite different, however, with those who postpone intercourse until after high school having particular characteristics that lead them to remain virgins when most adolescents are becoming sexually active. The only longitudinal study of these "postponers" suggests that adolescents who remained virgins into their twenties already differed from their peers psychologically in early adolescence (Jessor et al., 1983).

A large body of research has examined the correlates of timing of first intercourse (Hofferth, 1987). However, this research has often been limited in several respects. Much of the work has been atheoretical or descriptive, re- ducing the explanatory value of some findings. In addition, most studies have been cross-sectional, making it difficult to disentangle antecedents from consequences of early intercourse (Miller and Fox, 1987). Finally, research has tended to focus on girls over the age of 15 (Crockett, 1993). Research on boys and younger adolescents is needed to develop a comprehensive picture of adolescent sexual behavior.

Research on adolescent sexuality has also tended to focus on metropolitan samples, with rural samples being largely neglected. Typically, sexual activity rates among rural youth are assumed to be lower than among urban youth. A recent survey of junior high school students in three Eastern rural counties, however, indicated high rates of sexual activity, with over $40 \%$ of White eighth graders and $70 \%$ of Black eighth graders reporting intercourse (Alexander et al., 1989). Furthermore, teenage pregnancy is common in some rural communities (Vincent et al., 1987). Thus, many rural youth are sexually active at young ages and potentially at risk for pregnancy and sexually transmitted diseases. Research on rural samples is needed to identify antecedents common to youth in general, as well as any distinct processes leading to early intercourse among rural youth.

In light of these issues, the present study sought to extend previous research by using longitudinal data to identify predictors of the timing of first intercourse in a rural population. Both boys and girls were included so that the antecedents for each gender could be determined. Three timing groups were distinguished, reflecting initiation of intercourse in early adolescence, mid-adolescence, or later. Importantly, factors representing alternative explanations of adolescent sexual behavior were examined, providing a more comprehensive picture of the factors influencing timing of first intercourse.

\section{Explanations of Adolescent Intercourse}

Although the field of adolescent sexuality lacks a comprehensive theoretical framework, several hypotheses have emerged in the literature (Miller and Fox, 1987). One perspective emphasizes biological factors, with adolescent sexual activity being tied to the biological changes of puberty. In line with this perspective, pubertal hormones (especially androgens) appear to be associated with sexual motivation and intercourse experience in males (Udry et $a l ., 1985)$ and with sexual motivation and precoital sexual experience in females (Udry et al., 1986). Moreover, the timing of puberty appears to be associated with age at sexual initiation: early maturing girls tend to experience intercourse at younger ages than do later maturing girls (Magnusson, 1988). This may happen because early maturers are physically mature at a young 
early age and thus experience opportunities (and possibly pressure) to engage in intercourse before later maturers do. Based on these considerations, pubertal timing is expected to predict timing of first intercourse, with early maturers showing earlier timing than their later maturing peers

Other hypotheses focus on psychological or social processes. One perspective posits socialization as an important influence on sexual behavior (DiBlasio and Benda, 1990; Philliber, 1980). According to this social learning perspective, the presence of behavioral models for early or extramarital intercourse, along with exposure to permissive sexual norms, increases the likelihood of adolescent intercourse. Some studies have found, for example, that being the daughter of a teenage mother or having a sister who was pregnant as a teenager is associated with earlier intercourse among girls (East et at., 1993; Handler, 1990; Hogan and Kitagawa, 1985). The finding that adolescents in mother-only families are more likely to be sexually active (Miller and Bingham, 1989; Newcomer and Udry, 1987) has also been interpreted as a socialization effect (Kinnaird and Gerrard, 1986; Miller and Bingham, 1989), although it could also reflect less parental supervision and monitoring (Newcomer and Udry, 1987). In sum, according to the social learning perspective, having a mother or sister who was pregnant as a teenager and living in a nonintact family should be associated with earlier initiation of intercourse.

Another psychosocial explanation relates early intercourse to poor psychological adjustment. According to this perspective, early intercourse may reflect an attempt to compensate for inadequate social relationships or to counteract feelings of low self-esteem (Miller and Fox, 1987). Although support for this view is limited, the hypothesis is that poor social relationships and low self-esteem will be associated with earlier intercourse.

A third psychosocial perspective portrays adolescent intercourse as a form of norm-breaking or deviance. This perspective draws on social control theory (Hirschi, 1969), which postulates that people are naturally inclined toward deviance, but that bonds to conventional society cause most individuals to refrain from such behavior. Deviance, then, occurs among individuals whose bonds to conventional persons and social institutions are weak. If adolescent sexual intercourse represents a form of deviance, we would expect precocious intercourse to be associated with a weak attachment to parents and with low involvement in conventional institutions such as church and school. In support of this hypothesis, research has documented a link between poor parent-child relationships and sexual experience for girls (Fox, 1981; Chilman, 1986), as well as an association between low educational aspirations or performance and sexual activity for both sexes (Miller and Sneesby, 1988; Ohannessian and Crockett, 1992). In addition, adolescent sexual activity ap- pears to be associated with lower religiosity (Bingham et at., 1990; Jessor and Jessor, 1977).

A related perspective views adolescent sexual activity as part of a syndrome of problem behavior-behavior that violates social norms regarding appropriate adolescent behavior (Jessor and Jessor, 1977). If this is the case, early intercourse should be related to other indicators of this tendency toward norm breaking: for example, to substance use and delinquency. In accordance with this perspective, Jessor et at., (1983) found that timing of first intercourse was related to unconventionality and to norm-breaking assessed in early adolescence. Problem behaviors, including precocious sexual activity, have also been viewed as representing "transition-proneness" or the tendency to seek the privileges and status of adulthood (Jessor, 1984).

Finally, the literature indicates an association between timing of first intercourse and social class (Miller and Bingham, 1989; Hogan and Kitagawa, 1985; Scott-Jones and White, 1990). Although the reason for this association is not clear, several explanations are plausible. First, lower class youth may have limited opportunities for future success. From a social control perspective, limited opportunities could reduce their stake in the system and weaken their bonds to conventional society; under such conditions, the tendency to engage in proscribed behavior (e.g., premarital sex) should increase. Second, from a socialization perspective, lower class adolescents may have greater exposure to behavioral models of early Intercourse or to permissive sexual norms. Third, lower class adolescents may anticipate an early transition to adulthood and may engage in "adult" behaviors such as sex as a way to initiate this transition. Thus, while the mechanisms behind the association between social class and adolescent sexuality are not known, it is likely that social class effects operate through some of the processes already described.

The large number of variables associated with timing of first intercourse points to the operation of multiple influences rather than to a single unitary explanation. In fact, based on their review of the literature, Miller and Fox (1987) concluded that seeking to apply a single explanatory framework to adolescent sexuality may have little utility. For example, several factors may work synergistically to orient some adolescents toward early intercourse; furthermore, different adolescents may initiate intercourse for different reasons. These possibilities underscore the importance of a multivariate framework for understanding adolescent sexuality and the timing of sexual debut.

To address the issues outlined above, the present study examines the impact on timing of first intercourse of six sets of explanatory variables: pubertal timing, family socialization, psychosocial adjustment, bonds to conventional institutions, involvement in problem behavior, and socioeconomic status. 
"Timing" refers to an "early," "on-time," or "late" sexual debut in relation to the present sample. The following questions are addressed: First, which sets of explanatory variables, assessed in early adolescence, predict the timing of adolescent sexual debut? Second, which combination of factors best distinguish the three timing groups? Third, are the predictors of timing of first intercourse similar for girls and boys?

\section{METHOD}

\section{Sample}

Subjects in the present study were 289 White adolescents who were participating in a 5-year longitudinal study of rural adolescent development. The target population included all junior high school students in a single rural school district in the eastern United States. The district contained two junior high schools, each housing Grades 7-9. Thus the sample included three grade cohorts of adolescents who were followed for 5 years using a cohort-sequential longitudinal design (Baltes, 1969; Schaie, 1965).

The school district serves a geographically contained rural area composed of small boroughs and townships and located approximately three hours from the nearest urban center. Lack of public transportation further isolates the community from neighboring towns. The residents are middle to low income and primarily White. School census data for 1980 indicated that $69 \%$ of the adults had a high school education or less, the median household income was $\$ 14,400$, and the primary occupational categories were laborers and technical/clerical. Approximately $12 \%$ of families had incomes below the poverty level. Although there is heterogeneity with respect to socioeconomic status, the community as a whole is considered disadvantaged.

Data were collected through written survey questionnaires administered at school by project staff in the fall of each school year. Boys and girls were separated during survey administration, and procedures were monitored to maintain privacy. Confidentiality was assured, and no names were used on survey forms. All adolescents in the three grade cohorts were invited to participate. Approximately $90 \%$ of the target population participated in any given year. Excluded were adolescents who were absent on the day of the surveyor whose parents refused permission to participate. The sample for the present study includes 289 adolescents (166 girls and 123 boys) who had complete data on the variables of interest.

\section{Measures}

Most of the data for the present analyses came from the first survey, which was conducted in 1985 when the adolescents were in 7th-9th grades. As indicated below, the only exceptions to this rule were timing of first intercourse and pubertal timing.

\section{Timing of First Intercourse}

Timing of first intercourse was identified using annual survey data asking adolescents how often they had "been sexually active (had sex). ${ }^{5}$ Responses ranged on a 5-point scale from never to happens almost every day. By examining responses to this question over the six surveys, it was possible to determine the interval during which each adolescent experienced first intercourse. Age at the midpoint of this interval was taken as the age of first intercourse. In cases where the longitudinal data were inconsistent, an additional item (from the fourth annual survey) was used to resolve the inconsistency. This question asked adolescents how old they were when they first had sex.

Adolescents were then divided into three groups, based on their age at first intercourse. The majority of adolescents had reported first intercourse by age 17. Those who were still virgins at this point were placed in the "late" category. Those who were sexually active by this age were divided into "early" and "middle" groups, based on a median split performed separately for boys and girls. Specifically, "early" indicated that first intercourse occurred by the age of 14.75 years for boys and 15.5 years for girls; "middle" indicated the initiation of intercourse between the ages of 14.75 and 17 for boys and between the ages of 15.5 and 17 for girls; and "late" indicated an age at first intercourse of 17 years or more for both genders. Adolescents who were still virgins at the beginning of their senior year were placed in the "late" group. Use of timing categories rather than raw scores for age at first intercourse made it possible to retain these late initiators in analyses. Retention of the late initiators was important for statistical reasons, such as avoiding censoring in the sample, as well as substantive reasons. In particular, it enabled us to ascertain whether late initiators represented a distinct group in terms of their psychological and social characteristics.

${ }^{5}$ More explicit questions concerning sexual intercourse were not permitted by the school district. However, our confidence in the sex item was bolstered by a comparison of this item and items assessing precoital sexual behaviors (kissing and petting). The frequency distributions suggest that adolescents were able to distinguish between precoital behaviors and "having sex" (Ohannessian and Crockett, 1992). 


\section{Pubertal Timing}

Pubertal timing was assessed through a self-report measure included on the fourth annual survey. Boys and girls were asked whether they felt their pubertal development occurred earlier, about the same time as, or later than their peers of the same age and gender (Dubas et al., 1991). Possible responses included (1) much earlier (2) somewhat earlier (3) about the same time as (4) somewhat late; and (5) much later. Because few adolescents reported late pubertal timing, the two "late" categories were collapsed, yielding a four level response scale. Although less accurate than objective measures of pubertal timing, self-report measures appear to be reasonably valid, especially by midadolescence when most boys and girls have reached puberty (Dubas et al., 1991). The present measure came from the fourth annual survey when the adolescents were in Grades 10-12. Evidence of convergent validity was available for girls: the correlation between the four-level pubertal timing variable and self-reported age at menarche was $r=.61$.

\section{Socialization}

Family socialization for early sex and childbearing was indexed by three variables: having a mother who began child bearing as a teenager, having a sister who was pregnant as a teenager, and family structure. Adolescents were asked how old their mother was when her first child was born. This was computed by subtracting the age of the mother's oldest child from the mother's current age. The resulting scores were then dichotomized to reflect the presence or absence of a teenage mother. Adolescents were also asked whether any of their sisters had been pregnant as teenagers. Responses were scored dichotomously as yes or no. Finally, adolescents were asked which adults they lived with most of the time. Responses were coded as either intact (families with both natural parents) or non-intact (referring to all other family configurations $)^{6}$

Preliminary analyses indicated a high degree of collinearity between mother's teenage childbearing and family structure. In order to utilize information from both variables in the multivariate analyses, scores on these two variables were summed to create a composite risk index, ranging from 0 to 2 (subsequently referred to as "family risk"). Eighty-nine girls and 56 boys reported at least one risk factor. The variable "sister pregnant as a teenager" was retained as a separate variable. Nineteen girls and 6 boys reported a pregnant sister.

${ }^{6}$ Most adolescents in non-intact families lived with their mother only or with their mother and stepfather.

\section{Psychosocial Adjustment}

Adjustment was assessed by two scales, measuring self-esteem and the quality of peer relationships, respectively. Self-esteem was measured using the Rosenberg Self-Esteem Inventory, a 10-item Likert-type scale (Rosenberg, 1965). This widely used scale has been shown to predict external raters classification of patients as often gloomy or frequently disappointed, as well as level of depressive affect, physiological indicators of neurosis, frequency of reporting of psychosomatic symptoms, and positive peer group reputation. A typical item from this scale is, "On the whole, I am satisfied with myself." Responses range from (1) strongly agree to (4) strongly disagree. In the present study, alpha coefficients, based on the total sample, were .83 for females and .78 for males.

The quality of peer relationships was measured using a subscale of the Self-Image Questionnaire for Young Adolescents (SIQYA; Petersen et al., 1984). The Peer Relations Scale consists of 10 items (e.g., "I think that other people just do not like me"). Responses are scored on a Likert scale ranging from (1) very strongly agree to (6) very strongly disagree. Alpha coefficients for this scale were .82 for females and .76 for males.

\section{Conventional Bonds}

Conventional bonds was measured using 4 variables: attachment to parents, church attendance, participation in academic activities, and typical grades in school. Attachment to parents was assessed by the Family Relations subscale of the SIQYA (Petersen et al., 1984). The Family Relations scale consists of 17 items (e.g., "My parents are usually patient with me."). Alpha coefficients were .84 for boys and .89 for girls.

Church attendance was assessed by the question, "How often do you attend church?" Possible responses ranged from (1) never to (6) more than once a week. Involvement in academic activities was assessed by asking students to report how much time they spent each week in academic activities after school (e.g., doing homework, school projects, science fair, reading books). Responses ranged from 0 for never to 5 for many hours daily. students were also asked to report their typical grades in school. Responses for grades in school ranged from (1) mostly F's to (8) mostly A's. Self-reported grades are highly correlated with actual grade point average (Crockett et al., 1987). 


\section{Problem Behavior}

Minor delinquency was measured by 11 items drawn from the Primary Prevention Awareness, Attitude and Usage Scale (Swisher, 1979; Swisher et al., 1984). The items ranged from minor incidents (e.g., being sent out of a classroom by a teacher) to more serious incidents such as "stole something from a store." Items were scored using a 5-point frequency scale with responses ranging from (1) never to (5) happens every day. A final score for minor delinquency was computed by averaging each respondent's answers to the eleven items. Alpha coefficients for this scale were .79 for females, and .83 for males.

Substance abuse was measured with two additional items from the Primary Prevention Awareness, Attitude and Usage Scale (Swisher et al., 1984). These items assessed the frequency of getting drunk and getting high on drugs. Items were scored using a 5-point scale ranging from (1) never to (5) happens every day. Because the two scores were correlated $(r=.62)$, the items were averaged to form a single measure of substance abuse.

\section{Social Class}

Social class was indexed by mother's and father's educational attainment. Students reported how far each parent had gone in school using a 6-point scale ranging from (1) grade school only to (6) beyond college. Adolescents who were not living with both natural parents were asked to report the educational attainment of their resident stepparent instead of the missing parent. Scores for the two parents were averaged to yield a single composite measure of parental education. If adolescents were living with a single parent, however, that parent's educational attainment was used as the indicator.

\section{Data Analysis}

Data analysis proceeded in two steps. First, the association between timing of first intercourse and each set of hypothesized antecedents was examined using multivariate analysis of variance. Second, a discriminant function analysis was conducted to identify the constellation of variables that best discriminated among the different timing groups. All analyses were conducted separately for boys and girls, because there is evidence that biological and social factors differentially predict sexual intercourse for the two genders (Udry et al., 1985, 1986).

\section{RESULTS}

\section{Analysis of Variance}

To examine the relationship between timing of first intercourse and each set of hypothesized predictors, multivariate analyses of variance-MANOVAs (or analyses of variance [ANOVAs], as needed) - were conducted for each gender, with timing group as the independent factor. The multivariate effect was examined first, followed by any significant univariate effects. Because our intent was to test relationships derived from alternative hypotheses, univariate effects were examined even in the absence of a significant multivariate effect. Follow-up (-tests were also conducted to clarify significant univariate effects. The only exceptions to this procedure occurred with the family socialization variables, which were categorical. In these cases, chi-square analyses were substituted for the ANOVAs. Descriptive statistics for the three timing groups are reported in Tables I and II for girls and boys, respectively.

Among girls, significant multivariate effects of timing group were found for psychosocial adjustment, $F(4,324)=3.02, p<.05$, conventional bonds, $F(10,318)=2.61, p<.01$, and problem behavior, $F(4,324)=4.54, p<.01$. With respect to psychosocial adjustment, a significant univariate effect was found with peer relations, $F(2,163)=4.38, p<.05$. The means (Table I) indicated that the middle group had the highest scores, followed by the early and late groups. Follow-up tests indicated that the middle timing group reported significantly better peer relations than the late timing group; neither of these groups, however, differed from the early group. No group differences were found in self-esteem.

With regard to conventional bonds, significant univariate effects were found for academic activities and church attendance, $F(2,163)=3.52, p<$ .05 , and $F(2,163)=6.42, p<.01$, respectively. In the case of academic activities, follow-up tests indicated that girls in the middle timing group reported more frequent participation than did girls in the early timing group; neither of these groups differed from the late group, however (Table I). For church attendance, the late timing group reported more frequent attendance than either of the other two groups. The timing groups did not differ with respect to marks in school, educational plans, or reported quality of family relationships.

Finally, for problem behavior, only one indicator (substance use ) showed a significant univariate effect, $F(2,163)=9.09, p<.001$. Girls in the early intercourse group reported significantly more substance use than those in either of the other groups; girls in the middle and late groups did not differ from each other (Table I). 
Table I. Differences Among Girls with Early, Middle, or Late Timing of First Intercourse ${ }^{\mathrm{a}}$

\begin{tabular}{|c|c|c|c|c|}
\hline \multirow{2}{*}{ Construct/Variable } & \multicolumn{3}{|c|}{ Timing Groups } & \multirow{2}{*}{$F / \chi^{2}$} \\
\hline & $\begin{array}{c}\text { Early } \\
(n=60) \\
M \%\end{array}$ & $\begin{array}{c}\text { Middle } \\
(\mathrm{n}=63) \\
M \%\end{array}$ & $\begin{array}{c}\text { Late } \\
(n=43) \\
M \%\end{array}$ & \\
\hline $\begin{array}{l}\text { Biological factors } \\
\text { Pubertal timing }\end{array}$ & 287 & 294 & 295 & 32 \\
\hline SES & & & & \\
\hline Parent education & 3.05 & 3.28 & 3.29 & 1.22 \\
\hline $\begin{array}{l}\text { Socialization } \\
\text { Family risk }^{b} \\
\text { Pregnant sister }^{c}\end{array}$ & $\begin{array}{l}68 \% \\
15 \%\end{array}$ & $\begin{array}{l}57 \% \\
10 \%\end{array}$ & $\begin{array}{r}37 \% \\
9 \%\end{array}$ & $\begin{array}{c}12.53^{d} \\
1.17\end{array}$ \\
\hline $\begin{array}{l}\text { Adjustment } \\
\text { Peer relations } \\
\text { Self-esteem }\end{array}$ & $\begin{array}{l}4.48 \\
2.93\end{array}$ & $\begin{array}{l}4.64 \mathrm{a} \\
3.06\end{array}$ & $\begin{array}{l}4.20 \mathrm{~b} \\
2.97\end{array}$ & $\begin{array}{r}4.38^{d} \\
.92\end{array}$ \\
\hline $\begin{array}{l}\text { Conventional bonds } \\
\text { School grades } \\
\text { Academic activity } \\
\text { Educational plans } \\
\text { Church attendance } \\
\text { Family relations }\end{array}$ & $\begin{array}{l}6.33 \\
4.68 \mathrm{a} \\
4.27 \\
2.87 \mathrm{a} \\
4.29\end{array}$ & $\begin{array}{l}6.54 \\
5.19 \mathrm{~b} \\
4.46 \\
3.02_{\mathrm{a}} \\
4.54\end{array}$ & $\begin{array}{l}6.67 \\
5.02 \\
4.21 \\
3.86 \mathrm{~b} \\
4.58\end{array}$ & $\begin{array}{c}1.32 \\
3.52^{d} \\
.42 \\
6.42^{e} \\
2.22\end{array}$ \\
\hline $\begin{array}{l}\text { Problem behavior } \\
\text { Substance use } \\
\text { Minor delinquency }\end{array}$ & $\begin{array}{l}1.49 \mathrm{a} \\
1.60\end{array}$ & $\begin{array}{l}1.21 \mathrm{~b} \\
1.55\end{array}$ & $\begin{array}{l}1.05 b \\
1.46\end{array}$ & $\begin{array}{l}9.09^{f} \\
1.61\end{array}$ \\
\hline
\end{tabular}

${ }^{a}$ Means with different subscripts are significantly different based on StudentNewman-Keuls tests.

${ }^{b}$ Percent with either risk factor (nonintact family or mother was an early childbearer).

${ }^{c}$ Percent reporting a sister was pregnant as a teenager.

${ }_{p}<<.05$.

$\begin{aligned} p & <.05 \\ e_{p} & <.01\end{aligned}$

$f_{p}<.001$.

One additional finding involved family risk, the composite variable reflecting family structure and mother's age at the birth of her first child. This variable was significantly associated with timing of first intercourse, $\chi^{2}=12.53$, $d f=4, p<.05$. Inspection of the cross-tabulation indicated that greater family risk was associated with earlier timing of first intercourse. That is, girls in the early timing group were the most likely to be from a non-intact family or to have a mother who was a teenage childbearer (or both), followed by girls in the middle group, and finally, those in the late group.
Table II. Differences Among Boys with Early, Middle, or Late Timing of First Intercourse ${ }^{a}$

\begin{tabular}{lcccc}
\hline & \multicolumn{3}{c}{ Timing Groups } & \\
\cline { 2 - 4 } & $\begin{array}{c}\text { Early } \\
(n=50)\end{array}$ & $\begin{array}{c}\text { Middle } \\
(\mathrm{n}=53)\end{array}$ & $\begin{array}{c}\text { Late } \\
(n=20)\end{array}$ & \\
Construct/Variable & $M \%$ & $M \%$ & $M \%$ & $F / \chi^{2}$ \\
\hline Biological factors & & & & \\
$\quad$ Pubertal timing & 2.74 & 2.87 & 2.95 & 1.14 \\
SES & & & & \\
$\quad$ Parent education & 3.21 & 3.27 & 3.58 & 1.02 \\
Socialization & & & & \\
$\quad$ Family risk & & & & \\
Pregnant sister & $60 \%$ & $34 \%$ & $40 \%$ & $12.45^{d}$ \\
Adjustment & $4 \%$ & $6 \%$ & $5 \%$ & .15 \\
$\quad$ Peer relations & & & & \\
Self-esteem & 4.69 & 4.46 & 4.35 & 2.67 \\
Conventional bonds & 3.29 & 3.12 & 3.29 & 2.25 \\
$\quad$ School grades & & & & \\
Academic activity & 5.92 & 6.19 & 6.55 & 1.58 \\
$\quad$ Educational plans & 4.06 & 4.45 & 4.50 & 1.22 \\
$\quad$ Church attendance & 4.08 & 4.40 & 4.85 & 2.25 \\
Family relations & $2.60 \mathrm{a}$ & 3.13 & $3.60 \mathrm{~b}$ & 2.94 \\
Problem behavior & 4.49 & 4.53 & 4.75 & 1.21 \\
$\quad$ Substance use & & & & \\
Minor delinquency & $1.88_{\mathrm{a}}$ & $1.29 \mathrm{~b}$ & $1.03 \mathrm{~b}$ & $13.18^{e}$ \\
\hline
\end{tabular}

${ }^{a}$ Means with different subscripts are significantly different based on StudentNewman-Keuls tests.

${ }^{b}$ Percent with either risk factor (nonintact family or mother was an early childbearer).

${ }^{c}$ Percent reporting a sister was pregnant as a teenager.

${ }^{d} p<.05$.

$e_{p}<.001$.

In sum, effects for girls related to four of the six predictor sets: family socialization, psychosocial adjustment, conventional bonds, and problem behavior. Early timing of first intercourse was associated with lower participation in academic activities (relative to the middle group), greater family risk, and more frequent substance use. Late timing was associated with poor peer relationships (relative to the middle group ), high church attendance, and low family risk.

Among boys, a significant multivariate effect of timing group was found only for problem behavior, $F(4,238)=7.19, p<.0001$. The univariate tests for substance use and minor delinquency were both significant, $F(2,120)=$ 
$13.18, p<.0001$, and $F(2,120)=11.15, p<.0001$. Post hoc tests revealed that boys in the early timing group reported more frequent substance use and more delinquency than boys in the other two groups; boys in the middle and late groups did not differ significantly from each other (Table II). The multivariate effect of timing also approached significance in the case of psychosocial adjustment, $F(4,238)=2.37, p<.06$. Neither univariate effect reached significance, however, although a trend was found with peer relations, $F(2$, $120)=2.25, p<.1$.

The only other effect for boys was the significant association between timing group and family risk, $\chi^{2}=12.45, d f=4, p<.05$. Examination of the crosstabulation indicated that the primary difference was between the early timing group and the other two groups. Boys in the early group were more likely to have both risk factors (and consequently, less likely to have no risk factors) than boys in other two groups; in other words, they were more likely to come from a family that was non-intact and included a mother. who began childbearing as a teenager. Thus, among boys, significant timing group differences revolved around problem behavior and family characteristics: early timing of first intercourse was associated with more frequent, substance use and delinquent behavior but also with particular family and maternal characteristics. Boys in the middle and late timing groups generally did not differ from each other.

\section{Discriminant Function Analysis}

A second set of analyses was conducted to identify the constellation of antecedents that best discriminated among the three timing groups for each gender. For males and females separately, a discriminant function analysis was conducted, using the three timing categories as the discriminant groups. One significant discriminant function emerged for each gender. This function accounted for $71 \%$ of the variance for girls and $87 \%$ of the variance for boys. Results are summarized in Table III.

The coefficients for the canonical variable (which indicate the size of each predictor's contribution to the discriminant function) are presented in Table III. The coefficients are configured with reference to early timing, so that a positive coefficient indicates a positive association with earlier timing. Among girls, the variables that contributed substantially to the discriminant function (those with coefficients of .20 or more) were family risk, peer relations, educational plans, academic activities, church attendance, and substance use. More precisely, girls with earlier first intercourse were more likely to come from non-intact families or families of teenage mothers and to report better peer relations, less frequent participation in academic activities, lower church attendance, high educational plans, and more frequent substance use. Pubertal
Table III. Discriminant Function Analysis of Timing of First Sexual Intercourse by Gender and Virginity Status at Time $1^{\mathrm{a}}$

\begin{tabular}{|c|c|c|c|c|}
\hline & \multicolumn{2}{|c|}{ Girls } & \multicolumn{2}{|c|}{ Boys } \\
\hline & All & Virgins & All & Virgins \\
\hline $\begin{array}{l}\text { Biological Factors } \\
\text { Pubertal timing }\end{array}$ & -.10 & $(-.08)$ & -.24 & $(-.28)$ \\
\hline $\begin{array}{l}\text { SES } \\
\text { Parental education }\end{array}$ & -.05 & $(-.01)$ & .07 & $(.10)$ \\
\hline $\begin{array}{l}\text { Socialization } \\
\text { Family risk } \\
\text { Pregnant sister }\end{array}$ & $\begin{array}{l}.45 \\
.04\end{array}$ & $\begin{array}{l}(.46) \\
(.02)\end{array}$ & $\begin{array}{r}.58 \\
-.07\end{array}$ & $\begin{array}{r}(.76) \\
(-.02)\end{array}$ \\
\hline $\begin{array}{l}\text { Psychological adjustmen } \\
\text { Peer relations } \\
\text { Self-esteem }\end{array}$ & $\begin{array}{r}.45 \\
-.02\end{array}$ & $\begin{array}{r}(.57) \\
(-.02)\end{array}$ & $\begin{array}{l}.23 \\
.41\end{array}$ & $\begin{array}{l}(.32) \\
(.53)\end{array}$ \\
\hline $\begin{array}{l}\text { Conventional behavior } \\
\text { Marks in school } \\
\text { Educational plans } \\
\text { Academic activity } \\
\text { Church attendance } \\
\text { Family relations }\end{array}$ & $\begin{array}{r}-.07 \\
.21 \\
-.32 \\
-.50 \\
-.07\end{array}$ & $\begin{array}{r}(-.09) \\
(.19) \\
(-.23) \\
(-.55) \\
(-.06)\end{array}$ & $\begin{array}{r}-.22 \\
-.16 \\
-.27 \\
.07 \\
.22\end{array}$ & $\begin{array}{r}(-.37) \\
(-.17) \\
(-.29) \\
(.04) \\
(-.01)\end{array}$ \\
\hline $\begin{array}{l}\text { Problem behavior } \\
\text { Substance use } \\
\text { Minor delinquency }\end{array}$ & $\begin{array}{r}.37 \\
-.02\end{array}$ & $\begin{array}{r}(.32) \\
(-.03)\end{array}$ & $\begin{array}{l}.12 \\
.70\end{array}$ & $\begin{array}{r}(-.18) \\
(.72)\end{array}$ \\
\hline Timing Group & & Centroid & & entroid \\
\hline $\begin{array}{l}\text { Early } \\
\text { Middle } \\
\text { Late }\end{array}$ & & $\begin{array}{l}4 \\
12 \\
9\end{array}$ & & \\
\hline Wilk's lambda & & $1^{c}$ & & \\
\hline
\end{tabular}

${ }^{a}$ Coefficients are standardized.

$b_{p}<.01$.

timing was a weak contributor, with a coefficient of -.10. As indicated by the group means (centroids) on the discriminant function (bottom of Table III), the discriminant function for girls served to differentiate early, middle, and late groups, with the early and late groups being most clearly distinguished from each other.

Among boys, the discriminant function primarily distinguished the early timing group from the other two groups: as shown in Table III, the group centroid for the early group was positive and distant from those of the middle and late groups, which were negative and close to each other. Turning 
to the coefficients, pubertal timing, family risk, self-esteem, peer relations, marks in school, academic activities, family relationships, and minor delinquency contributed most strongly to the discriminant function. Educational plans and substance use were weaker contributors. Again, a positive coefficient indicated a positive association with earlier timing. Thus, boys in the early timing group were more likely to come from non-intact families or to have a mother who began childbearing as a teenager; they also tended to report earlier pubertal timing, better peer relations, higher self-esteem, poorer grades, somewhat lower educational plans, less involvement in academic activities, more minor delinquency, somewhat higher substance use, and better family relationships.

\section{Prospective Analyses}

The analyses reported thus far included all adolescents with complete data on the variables of interest. A small number of these adolescents ( 6 girls and 20 boys) were already sexually active at the time of the first survey (Time 1) when most of the predictor variables were assessed. Thus, for these youth, first intercourse preceded measurement of the predictor variables. To permit a prospective investigation of factors predicting timing of first intercourse, the discriminant function analyses were repeated for the 160 girls and 103 boys who were virgins at Time 1 . The risk in this analysis is that, by censoring the sample, we introduce bias. It should also be noted that effects of pubertal timing could not be analyzed prospectively, because data on pubertal timing were not available at Time 1 .

The discriminant function analysis based on the prospective sample also yielded a single significant function for each gender. Among girls, the results of the prospective analysis were almost identical to those in the total sample. The coefficients increased or decreased slightly, but the overall pattern was the same, with the same variables contributing to the discriminant function (Table III). This would be expected since the only 6 girls were excluded from the prospective analysis.

Among boys, the results of the prospective analysis were similar to those of the total sample with two exceptions. First, family relations, which contributed to the discriminant function in the total sample of boys, failed to contribute in the prospective sample. Second, the coefficient for substance use which was small and positive in the total sample analysis, was negative in the prospective analysis. These results suggest that the role of family relationships and substance use in predicting timing of first intercourse may differ for virgin and nonvirgin boys. Among boys who are virgins, family relationships are not predictive of first intercourse, and substance use predicts a later (rather than earlier) sexual debut (Table III)

\section{DISCUSSION}

The purpose of the present study was to identify personal and family characteristics associated with an early, on time, or late initiation of sexual intercourse among rural adolescents. Six sets of characteristics were examined, representing constructs hypothesized to influence timing of first intercourse: pubertal timing, family socialization, psychosocial adjustment, bonds to conventional institutions, involvement in problem behavior, and socioeconomic status. Results for girls indicated a possible role of family socialization, psychosocial adjustment, conventional bonds, and problem behavior in the timing of first intercourse. Results for boys consistently indicated the importance of family socialization and problem behavior. The findings provide support for four explanatory perspectives: social learning theory, problem behavior theory, social control theory, and for boys, biological processes. Family socialization was consistently predictive of timing of intercourse for both genders. In other words, living in a non- intact family and having a mother who was a teenage parent were associated with an earlier sexual debut among both boys and girls. From asocial learning perspective, these family circumstances are viewed as providing exposure to permissive sexual norms and perhaps to maternal models of early or non-marital intercourse (e.g., Miller and Bingham, 1989; Kinnaird and Gerrard, 1986). Our findings are consistent with this interpretation, although modeling and perceived norms were not directly assessed in the present study. It is also possible that the findings reflect reduced parental monitoring (and increased opportunities for engaging in intercourse ), rather than social learning per se (e.g., Newcomer and Udry, 1987). This alternative explanation was not evaluated in this study and must await future research.

It is also interesting that having a sister who was pregnant as a teenager was not a predictor of timing for either gender. Although having a sister who became pregnant would seem to provide exposure to role models for early intercourse, this did not significantly affect timing of first intercourse in the present study. It is possible that the impact of a pregnant sister is expressed in other aspects of sexual behavior such as use of contraceptives or pregnancy decisions. Further, because only a small number of adolescents reported that a sister had been pregnant, the likelihood of finding a significant effect was reduced. Other studies in which a larger number of adoles- 
cents report pregnant sisters are needed to fully evaluate the impact of this variable (e.g., East et al., 1993).

The problem behavior perspective also received some support. Consistent with previous findings (Jessor and Jessor, 1975, 1977), a relationship was observed between adolescent sexual activity and involvement in other socially proscribed behaviors. The key behavior appeared to be substance use: for both genders, more frequent substance use was associated with an earlier sexual debut in the multivariate analysis of variance. Further, among boys, earlier first intercourse was associated with greater involvement in minor delinquency, as would be predicted by problem behavior theory.

For girls, the support for problem behavior theory was less consistent. Earlier sexual initiation was associated with more frequent substance use, as predicted, but not with other forms of misconduct. Thus, girls who had sex at younger ages did not seem to show a generalized pattern of norm breaking in the way boys did. The girls' pattern may reflect the notion of "transitionproneness" (Jessor, 1984), which suggests that involvement in problem behaviors represent a push to attain adult status. For girls, this push appears to be expressed in earlier sexual debut and more frequent substance use (which represent conventional adult behaviors) but not in antisocial behavior .

The role of social control (bonds to conventional persons and institutions) in delaying sexual initiation was supported primarily for girls. Among girls, frequency of church attendance and involvement in academic activities were consistently associated with later sexual initiation. Both of these factors have been found to be associated with a later onset of intercourse in other research (Bingham et al., 1990; Jessor et al., 1983; Miller and Sneesby, 1988). From asocial control perspective (Hirschi, 1969), each of these factors reflects bonds to conventional society that serve to deter individuals from transgressing social norms. Specifically, church attendance may reflect personal beliefs condemning proscribed behavior (including premarital intercourse) and may also reduce the time and opportunity for proscribed behavior. Similarly, academic performance may reflect an investment in conventional goals that would be jeopardized by involvement in "deviant" behavior.

The role of conventional attachments was less clearly supported for boys. None of these variables was associated with timing of first intercourse in the MANOVAs, although a statistical trend was found for church attendance. Results of the discriminant function analysis indicated that several of them (particularly school grades, and academic activities) contributed to the function discriminating among timing groups, but, even here, the contribution was small.

One possible explanation for the differential role of conventional bonds among boys and girls involves the sexual double standard. Early sexual ac- tivity is more strongly proscribed for girls than for boys. Thus, whereas girls who have strong attachments to conventional institutions may feel compelled to delay sexual activity in order to conform to conventional social norms, boys (for whom sexual activity is less "deviant") may not feel conventional bonds have implications for their sexual behavior.

In contrast, support for the role of biological processes was found only among boys. Even for boys, the support was not consistent: pubertal timing was not significantly associated with timing of intercourse in the ANOVA, but it did contribute to the discriminant function. In this case, earlier timing of puberty was associated with earlier timing of first intercourse. This association is in accordance with hypotheses and some prior research (e.g., Udry et al., 1985). That no association was found in the bivariate analyses, however, suggests that the effect of pubertal timing may be subtle and observable only in the context of other variables.

It is puzzling, however, that an effect of pubertal timing emerged only for boys. An association between pubertal timing and intercourse has been reported in other research on girls (e.g., Stattin and Magnusson, 1990; Udry and Billy, 1987). Differences in samples and measures may account for these discrepancies. In particular, it should be recalled that the present measure of pubertal timing was based on self-reports of perceived timing relative to samesex peers; thus the results may be subject to biases in reporting. Further, the direction of effects is unclear in the present analyses, because pubertal timing was assessed at the fourth survey when many of the adolescents were already sexually active. Given these caveats, the findings for pubertal timing should be interpreted with caution.

No support was found for the other two explanatory models. Although peer relations showed a significant association with timing of first intercourse for girls, and contributed to the discriminant function for both genders, the direction of these relationships was contrary to prediction. That is, poorer peer relations was associated with later timing of first intercourse. A similar picture emerged for self-esteem: although it was as a strong contributor to the discriminant function for boys, higher self-esteem was associated with earlier timing of intercourse. These results militate against attributing early intercourse to poor psychosocial adjustment. Rather, it appears that positive social relations and high self-esteem contribute to earlier intercourse, perhaps because they increase the likelihood of finding a sexual partner (see also Jessor and Jessor, 1975). In this regard, it would be useful to examine the association between these variables and heterosocial variables such as dating or having a boyfriend or girlfriend, which should themselves be predictive of timing of intercourse. 
The socioeconomic model received no support in either set of analyses. The lack of support for this model is puzzling, because a relationship between SES and adolescent sexual activity has been observed in other research (e.g., Hogan and Kitagawa, 1985; Miller and Bingham, 1989). Given that our measure of SES was based on adolescents' reports of parents' educational attainment, measurement unreliability cannot be ruled out. Other analyses with the present sample, however, indicate that parents' educational attainment significantly predicts other important adolescent outcomes (e.g., Crockett \& Bingham, 1994), so measure unreliability is unlikely to be the full explanation.

Alternatively, the lack of an association between SES and timing of first intercourse may be a function of the local community context. The adolescents in the sample all attended the same junior high and high schools in a rural, racially homogeneous community. Thus, they were exposed to the same peer norms of behavior, and under these circumstances, social class differences in timing of first intercourse may have been attenuated. Further research with rural populations is needed to replicate this finding. If the present findings are replicated, the processes that make social class less important in rural communities need to be investigated.

The present results point to a number of interesting differences among adolescents experiencing an early, middle, or late sexual debut relative to their peers. Among girls, those in the early group appear to be characterized by lower academic involvement, higher substance use, and a greater likelihood of coming from a family background conducive to early sexual activity; those in the middle group are characterized by positive peer relationships and high academic involvement; and those in the late group are characterized by poorer peer relationships and more frequent church attendance. Among boys, the main differences were between the early timing group and the other groups. Boys experiencing an early sexual debut were more involved in substance use and delinquent behavior and more likely to come from a family background involving non-intact family structure and a mother who was an early childbearer. Boys in the middle and late groups were similar to each other on most counts.

Many of these findings dovetail with those of Jessor and colleagues. For example, Jessor et al. (1983) found that youth who remained virgins into their twenties had higher educational attainment, were more religious, had experimented less with substances, and felt less competent with peers of the opposite sex than those who became sexually active as teenagers. Similar patterns were identified in the present analyses. The present results also parallel those of Jessor et al. (1983) in that the social and psychological differences between timing groups were, in most cases, observed prior to the onset of sexual activity.
More broadly, the findings suggest that the timing of adolescents' sexual initiation is influenced by a multiplicity of factors that may not be covered by a single theoretical model. Thus, they underscore the need for an eclectic model that recognizes these diverse processes. As Miller and Fox (1987) have argued, attempting to apply a unitary model to adolescent sexuality may have little utility. Although continued research on particular theoretical explanations is needed to document the specific processes contributing to timing of first intercourse, broader models will enable us to predict timing of first intercourse with greater precision.

The present results depend, of course, on the measure of sexual intercourse utilized in the study. That we had longitudinal data and could aggregate information on "having sex" over multiple years strengthens our confidence in the measure and the findings. Nonetheless, the field would benefit from the use of more explicit measures of sexual intercourse, where such measures are permitted.

Finally, the present study says little about adolescents' experiences after they initiate intercourse. Prior research indicates that many adolescents do not have sex again for months or even years after their first sexual encounter and that sexual activity is often sporadic; other adolescents, of course, may develop a steady relationship in which sex is more frequent. Thus, in addition to further studies of first intercourse, future research should address the issues of frequency and patterning of adolescent sexual activity and their consequences for subsequent health and well-being.

\section{ACKNOWLEDGEMENT}

This research was supported by Grant No. APR 000933-01 to J. R. Vicary from the Office of Adolescent Pregnancy Programs. We gratefully acknowledge the contributions of the participating students and schools as well as the staff of the Rural Adolescent Development Study.

\section{REFERENCES}

Alexander, C. S., Ensminger, M. E., Kim, Y. J., Smith, B. J., Johnson, K. E., and Dolan, L. J. (1989). Early sexual activity among adolescents in small towns and rural areas: Race and gender patterns. Family Plan. Perspect. 21: 261-266.

Baltes, P. B. (1968). Longitudinal and cross-sectional sequences in the study of age and generational effects. Human Develop. 11: 145-171.

Bingham, C. R. (1989). AIDS and adolescents: Threat of infection and approaches for prevention. J. Early Adoles. 9: 50-66.

Bingham, C. R., Miller, B. C., and Adams, G. R. (1990). Correlates of age at first sexual intercourse in a national sample of young women. J. of Adoles. Res. 5: 18-33.

Chilman, C. S. (1986). Some psychosocial aspects of adolescent sexual and contracep- 
tive behaviors in a changing American society. In Lancaster, J. B., and Hamburg, B. A. (eds.), School-Age Pregnancy and Parenthood: Biosocial Dimensions. Aldine de Gruyter, New York.

Crockett, L. J. (1993). Early adolescent family formation. In Lerner, R. M. (ed.), Early Adolescence: Perspectives on Research, Policy and Intervention. Erlbaum, Hillsdale, NJ.

Crockett, L. J., and Bingham, C. R. (1994). Family influences on girls' sexual experience and pregnancy risk. Manuscript under review.

Crockett, L. J., Schulenberg, J. E., and Petersen, A. C. (1987). Congruence between objective and self-report data in a sample of young adolescents. J. Adoles. Res. 2(4): 383-392.

D'Augelli, A., and Bingham, C. R. (1993). Intervention to prevent HIV infection in young adolescents. In Lerner, R. M. (ed.), Early Adolescence: Perspectives on Research, Policy and Intervention. Erlbaum, Hillsdale, NJ.

DiBlasio, F. A., and Benda, B. B. (1990). Adolescent sexual behavior: Multivariate analysis of a social learning model. J. Adoles. Res. 5: 449-466.

Dubas, J. S., Graber, J. A., and Petersen, A. C. (1991). A longitudinal investigation of adolescents' changing perceptions of pubertal timing. Develop. Psych. 27(4): 580-586.

East, E L., Felice, M. E., and Morgan, M. C. (1993). Sisters' and girlfriends' sexual and child-bearing behavior: Effects on early adolescent girls' sexual outcomes. J. Marriage Family, 55: 953-963.

Fox, G. L (1981). The family's role in adolescent sexual behavior. In Ooms, L (ed.), Teen age Pregnancy in a Family Context: Implications for Policy. Temple University Press, Philadelphia, PA.

Handler, A. (1990). The correlates of the initiation of sexual intercourse among young urban black females. J. Youth Adoles. 19: 159-170.

Hayes, C. D. (ed.). (1987). Risking the Future: Adolescent Sexuality, Pregnancy and Childbearing (Vol. 1). National Academy Press, Washington, DC.

Hirschi, L. (1969). Causes of Delinquency. University of California Press, Berkeley.

Hofferth, S. L. (1987). Factors affecting initiation of sexual intercourse. In Hofferth, S. L. and Hayes, C. D. (eds.), Risking the Future: Adolescent Sexuality, Pregnancy and Childbearing (Vol. 2): Working Papers and Statistical Appendices. National Academy Press, Washington, DC

Hogan, D., and Kitagawa, E. (1985). The impact of social status, family structure and neighborhood on the fertility of black adolescents. Am. J. Sociol. 90: 825-855.

Jessor, R. (1984). Adolescent development and behavioral health. In Matarazzo, J. D., Weiss, S. M., Herd, J. A., Miller, N. E., and Weiss, S. M. (eds.), Behavioral Health: Handbook of Health Enhancement and Disease Prevention. Wiley, New York.

Jessor, R., and Jessor, S. L. (1977). Problem Behavior and Psychosocial Development: A Longitudinal Study of Youth. Academic Press, New York.

Jessor, S. L., and Jessor, R. (1975). Transition from virginity to nonvirginity among youth: A social-psychological study over time. Develop. Psych. 11(4): 473-484.

Jessor, R., Costa, F:, Jessor, S. L., and Donovan, J. E. (1983). Time of first intercourse: A prospective study. J. Personal. Social Psychol. 44: 608-628.

Jones, E. F:, Forrest, J. D., Goldman, N., Henshaw, S., Lincoln, R., Rosoff, J. I., Westoff, C. F:, and Wulf, D. (1986). Teenage Pregnancy in Industrialized Countries. Yale University Press, New Haven.

Kinnaird, K. L., and Gerrard, M. (1986). Premarital sexual behavior and attitudes toward marriage and divorce among young women as a function of their mothers' marital status. J. Marriage Family 48: 757-765.

Magnusson, D. (1988). Individual development from an interactional perspective: A longitudinal study. Erlbaum, Hillsdale, NJ.

Miller, B. C., and Bingham, C. R. (1989). Family configuration in relation to the sexual behavior of female adolescents. J. of Marriage Family 51: 499-506.

Miller, B. C., and Fox, G. L. (1987). Theories of adolescent heterosexual behavior. J. Adoles. Res. 2(3): 269-282.

Miller, B. C., and Sneesby, K. R., (1988). Educational correlates of adolescents' sexual attitudes and behavior. J. Youth Adolesc. 17: 521-530.

Newcomer, S. E, \& Udry, J. R. (1984). Mother's influence on the sexual behavior of their teenage children. J. Marriage Family 45: 477-485.

Newcomer, S., and Udry, J. R. (1987). Parental marital status effects on adolescent sexual behavior. J. Marriage Family 49: 235-240.

Ohannessian, C. M., and Crockett, L. J. (1992). A longitudinal investigation of the relationship between educational investment and adolescent sexual activity. Unpublished manuscript, under review.

Petersen, A. C., Schulenberg, J. E., Abramowitz, R. H., Jarcho, H., and Offer, D. (1984). A self-image questionnaire for young adolescents (SIQYA): Reliability and validity studies. J. Youth Adolesc. 13: 93-111.

Philliber, S. G. (1980). Socialization for childbearing. J. Social Issues 36: 30-44.

Rosenberg, M. (1965). Society and the Adolescent Self-Image. Princeton University Press, Princeton, NJ.

Schaie, K. W. (1965). A general model for the study of developmental patterns. Psychol. Bull. 64: 92-107.

Scott-Jones, D., and White, A. B. (1990). Correlates of sexual activity in early adolescence. J. Early Adolesc. 10: 221-238.

Sonnenstein, F. L., Pleck, J. H., and Ku, L. C. (1989). Sexual activity, condom use and AIDS awareness among adolescent males. Family Plan. Perspect. 21: 152-158.

Stattin, D., and Magnusson, D. (1990). Pubertal maturation in female development. Er1baum, Hillsdale, NJ.

Swisher, J. (1979). Primary Prevention Awareness, Attitude and Usage Scale (PPAAUS). Author, State College, PA.

Swisher, J., Shute, R. E., and Bibeau, D. (1984). Assessing drug and alcohol abuse: An instrument for planning and evaluation. Measure. Evaluat. Counsel. Develop. 17: 91-97.

Udry, J. R., \& Billy, J. O. G. (1987). Initiation of coitus in early adolescence. Am. Social. Rev. 52: 841-855.

Udry, J. R., Billy, J. O. G., Morris, N. M., Groff, L. R., and Raj, M. H. (1985). Serum androgenic hormones motivate sexual behavior in adolescent boys. Fertil. Steril. 43(1): 90-94.

Udry, J. R., Talbert, L. M., and Morris, N. M. (1986). Biosocial foundations for adolescent female sexuality. Demography 23(2): 217-228.

Vincent, M. L., Clearie, A. F., and Schlucter, M. D. (1987). Reducing adolescents preg nancy through school and community-based education. J.A.M.A. 257: 3382-3386.

Zelnik, M., and Shah, E K. (1983). First intercourse among young Americans. Family Plan. Perspec. 15(2): 64-70. 